\title{
LENGUAJE OFENSIVO Y SU TRADUCCIÓN EN LOS TEXTOS LITERARIOS
}

\author{
Nataliia Volynets \\ Ph.D., Profesora de español, Departamento de la lengua española y francesa, \\ Universidad nacional lingüística de Kyiv, Ucrania \\ e-mail: nataliia_volynets@ukr.net,orcid.org/0000-0003-0311-5471
}

\section{Resumen}

La traducción literaria es un verdadero "arte verbal" (Vinogradov, 1978), que requiere del traductor las habilidades adecuadas y un profundo conocimiento enciclopédico para reproducir y transmitir la esencia ideológica de la obra original. Gracias a la traducción literaria las cultura se enriquecen y se complementan una a otra. En la lieratura moderna española y latinoamericana se utiliza cada vez más el lenguaje ofensivo, cuya reproducción adecuada en otro idioma es uno de los problemas actuales de los estudios de traducción. Normalmente, los autores utilizan el lenguaje soez para el discurso vivo de los personajes, la creación de un cierto efecto emocional, la imagen de los personajes.

La reproducción de las unidades comunicativas de este campo léxico-semántico en las traducciones provoca ciertas dificultades, por su contenido semántico-denotativo que no coincide en diferentes idiomas. Por tanto, el traductor debe buscar un equivalente funcional que pueda reproducir de forma natural el lenguaje malsonante, sin suavizarlo ni reforzarlo, y transmitir el efecto que el autor ha creado en su obra. El artículo presenta interpretaciones modernas del concepto del lenguaje soez o malsonante, también describe los problemas y métodos de traducción de este vocabulario al ucraniano.

Palabras clave: el español, el ucraniano, lenguaje malsonante, traducción literaria, estrategias de la traducciín del lenguaje ofensivo.

\section{DOI: https://doi.org/10.23856/4613}

\section{Introducción}

Entre muchos tipos de traducción, las traducciones de los textos literarios se destacan por su especial papel y significado, ya que este tipo de traducción es una de las manifestaciones más llamativas de la interacción de diferentes culturas lingüísticas. La traducción artística es una forma de arte literario donde "los libros ajenos se vuelven propios" (Duhamel, 1983: 164), gracias a la cual el lector puede apreciar riquezas espirituales y culturales creados en las obras de autores extranjeros. El autor crea el texto y lo llena de diversos medios de expresión, y es una especie del desafío para el traductor, ya que es necesario reproducir no solo el contenido de la obra original con su colorido nacional e histórico, sino también transmitir lo emocional y conservar el estilo individual del autor.

Según muchos científicos los estudios de traducción, la traducción literaria es una de las más complejas, porque la obra de arte en sí es una estructura compleja con diferentes niveles interrelacionados (Novikov, 2003) (sociocultural, ideológico, de género y de estructura composicional y de lengua) y refleja visión del mundo, visión poética de la realidad no solo del autor, sino también de las personas que hablan un determinado idioma (Nekryach, 2008).

Son diversos los autores como V. Vinogradov, U. Eko, T. Nekryach, A. Popovych, A. Fedorov y otros que han estudiado problemas y peculiaridades de la traducción literaria. 
Los expertos en teoría de la traducción como N. Garbovskiy, V. Komissarov, A. Fédorov generalmente distinguen las siguientes características de la traducción literaria: conservación del colorido nacional e histórico en la traducción, adecuación y equivalencia de las unidades lingüísticas utilizadas, contexto del autor y contexto del traductor, combinación de contenido y de forma, conservación del estilo individual del autor y la carga semántica, reproducción de la distancia temporal y espacial, etc. Todo esto es la esencia profunda de los problemas científicos de los estudios contemporráneos de la traducción. Nuestro estudio acarrea una de las cuestiones actuales, es decir, las peculiaridades de la traducción del lenguaje ofensivo.

El famoso científico ruso V. Modestov señala que el lenguaje malsonante, soez es una parte integral de la vida humana y se refleja en la literatura de diferentes pueblos. Así, en el proceso de traducción de las obras literarias, a menudo surgen dificultades asociadas con la reproducción de este tipo de lenguaje, que los autores utilizan con el cierto fin estilístico y emocional y la creación de diversas imágenes artísticas. Por tanto, a la hora de traducir, este conjunto léxico-semántico de vocabulario debe cumplir la misma función y ser percibido de la misma forma que en la obra original (Modesov, 2006).

Los investigadores coinciden en que el criterio principal para traducir tal nivel de vocabulario es la equivalencia pragmática, que consiste en encontrar un equivalente emocional en lugar de literal. Es por eso que la traducción de tales unidades comunicativas requiere que el traductor no solo comprenda qué función estilística desempeña una palabrota en la obra para guardar el efecto emocional del original, sino también que tenga en cuenta varios factores extralingüísticos como normas morales, éticos y culturales, tradiciones nacionales, creencias religiosas, opiniones sociopolíticas, etc. de los lectores de la traducción, para que la reproducción de dicho vocabulario no se convierta en un simple insulto.

\section{Interpretación del concepto de "lenguaje malsonante"}

Destacados científicos ucranianos y extranjeros como L. Stavytska, S. Formanova, M. Tkachivska, V. Mokienko, V. Zhelvis, O. Plutsero-Sarno, T. McEnry, P. Anderson, P. Trajil, K. Allan y K. Barridge y otros han estudiado el lenguaje ofensivo.

Hoy en día, los científicos incluyen vocabulario obsceno, abusivo, tabú, invectivas, jergas, vulgarismos, jergas, tacos, palabrotas, blasfemias y ofrecen diferentes clasificaciones de tales unidades comunicativas.

La reconocida investigadora ucraniana L. Stavytska en su trabajo "Lengua ucraniana sin tabúes. Diccionario de lenguaje obsceno y sus equivalentes", define el lenguaje obsceno como palabras y expresiones tabú (prohibido), obsceno (inédito, obsceno, no literario). L. Stavytska valora la obscenidad como el uso del lenguaje que se considera repulsivo, obsceno. Es interesante notar que a pesar de la semántica transparente, esta palabra es ignorada al considerar el vocabulario correspondiente en la sección "vulgarismos", lo que provoca una difusión terminológica no deseada y un caos en el microsistema terminológico: juramento - invectiva vocabulario obsceno - palabrota. Según la investigadora, el concepto de "vocabulario obsceno" es más amplio que el concepto de "vocabulario de palabrotas", porque el vocabulario de palabrotas es un componente de obsceno (Stavytska, 2008:16-19).

L. Kleputs expresa una opinión similar, señalando que el concepto de vocabulario "no normativo" a menudo se pone al mismo nivel con los conceptos de vulgar, obsceno, grosero. Sin embargo, como señala la investigadora, tales epítetos solo se les pueden dar a algunos subsistemas de esa campo de vocabulario. Las observaciones de la investigadora parecen interesantes 
al respecto que es sumamente difícil clasificar el lenguaje malsonante debido a los procesos de migración de ciertas unidades léxicas de un grupo a otro (Kleputs, 2009).

El investigador ruso V. Zhelvis unió todos los tipos de agresión lingüística bajo el término "invectiva". El científico considera este concepto en dos sentidos: 1) cualquier manifestación verbal de agresión hacia el oponente y 2) violación verbal de un tabú ético llevada a cabo por medios del lenguaje tabú (Zhelvis, 2001:75).

En su estudio, doctora S. Formanova propone un enfoque en el que los conceptos de "invectiva", "insulto", "juramento" se consideran sinónimos, porque, como ella señala, es nominación vulgar, malsonante o tabú del destinatario o tercera persona, que tiene semántica evaluativa y contiene insultos (Formanova, 2013).

A. Zhusupova define el lenguaje soez como un grupo socialmente limitado de palabras que están fuera del lenguaje literario. La investigadora popone considerar argo, jerga, vulgarismo como vocabulario no normativo (Zhusupova, 2014).

El lingüista británico Tony McEnry cree que el lenguaje soez significa cualquier palabra o frase que, cuando se usa en una conversación cortés, puede ofender. El profesor destaca las malas palabras como uno de los ejemplos de lenguaje soez (McEnry, 2006).

Los investigadores L. Anderson y P. Trudgill tienen una opinión diferente. Bajo el vocabulario no normativo entienden declaraciones que son tabú o estigmatizadas (tienen un estereotipo negativo) en una cultura particular. Estos lingüistas creen que tales palabras no deben tomarse literalmente. En su opinión, tal vocabulario sirve para expresar emociones fuertes, estado de ánimo. Un ejemplo interesante en este sentido es la palabra "mierda", que pertenece al vocabulario tabú, ya que está asociada a la función escatológica, es decir, fisiológica del cuerpo humano. Los científicos argumentan que cuando esta palabra se usa para insulto exclamativo, su significado literal y de referencia se pierde, en cambio adquiere un color emocional negativo (Anderson y Trajil 1992: 53).

A. Shippers cree que el vocabulario abusivo y no normativo incluye palabras que se usan en sentido figurado y contienen elementos tabú (Schippers, 2014).

Científico J. Avila-Cabrera (2015) interpreta este concepto de una manera ligeramente diferente. Incluye palabras abusivas, vulgares en la categoría de lenguaje ofensivo, que pueden ser consideradas en el caso de su uso en el discurso como desprecio o insulto al interlocutor (Avila-Cabrera,2015).

Así pues, el lenguaje ofensivo forma una parte bastante grande de vocabulario del lenguaje, que cubre varios registros, que incluyen dialectos sociales (jerga, argo, coloquialismo y sleng), así como vocabulario estilísticamente reducido (vocabulario obsceno, invectivas, vulgarismos, palabrotas). Es el contexto el que determina la pertenencia de este tipo de palabras a un grupo particular.

\section{Métodos y estrategias de traducción del lenguaje malsonante}

Uno de los principales problemas a la hora de traducir lenguaje ofensivo en una obra de arte es la búsqueda de esos equivalentes que reproducirían naturalmente ese vocabulario del original en la cultura de los destinatarios.

La tarea principal del traductor, trabajando con este tipo de unidades comunicativas, según el lingüista D. Buzadzhi, es hacer que el vocabulario obsceno desempeñe la misma función que en el texto original, y que sea percibido tanto por los lectores de la traducción como por los lectores original, independientemente de la etimología de estas palabras en el idioma original. El experto enfatiza que la palabra abusiva no debe perder el componente 
cognitivo de su significado (si es importante), y la traducción no debe fortalecerlo ni suavizarlo (Buzadzhi, 2006).

Los científicos españoles Rojo y Valenzuela destacan que en ocasiones el

traductor intenta resolver rápidamente el problema de reproducción de la blasfemia y recurre al uso del inglés, perdiendo la naturalidad del discurso (López et al, 2000).

Al estudiar la investigación sobre el tema de la reproducción del lenguaje

malsonante, podemos identificar las siguientes estrategias básicas de traducción del vocabulario abusivo del español al ucraniano: calco o traducción literal, perífrasis, uso de equivalente dinámico, sustitución eufemística y disfémica.

1. El calco. La traducción literal fue destacada por los lingüistas franceses J. Darbelne y J.-P. Vine. Esta técnica de traducción consiste en la traducción directa de una palabra o expresión del idioma de origen al idioma de traducción. Los expertos señalan que la traducción literal no siempre es posible, ya que a menudo no existe un análogo léxico adecuado en el idioma de la traducción. Según el investigador V. Modestov hay casos cuando la traducción literal puede suavizar o intensificar el significado de una determinada unidad léxica ofensiva (Modestov, 2006: 246). Vemos algunos ejemplos de tal estrategia de traducción.

¿Así se llama él, de veras, con esa lisoruta? ¿Rascachucha? (Vargas Llosa, 2013 :358)

- A що, у нього справді таке сороміцьке прізвище? Піхвачоса? (Варгас Льoca, 2014: 91)

- Mírame bien, viejo de mierda. (Ruíz Safón, 2016 :1306)

- Слухай мене уважно, ти, старе лайно (Руїс-Сафон, 2018:517)

- Alicia, si no sale usted de ahí voy a prenderle fuego a este montón de mierda (Ruíz Safón, 2016: 1655)

- Алісіє, якщо ти зараз не покажешся, я підпалю всю цую купу лайна (Pуї-Сафон, 2018: 653)

- Probablemente una puta cara (Ruíz Safón, 2016 : 1631)

- Якась елітна шльондра, мабуть (Руїс-Сафон, 2018: 644)

En estos ejemplos, gracias a la traducción literal, fue posible guardar y transmitir la información emocionalmente expresiva del mensaje, para conservar las características comunicativas de los personajes.

2. Perífrasis (reformulación). Esta técnica le permite transmitir los pensamientos del autor en expresiones similares pero no precisas. Gracias a esta decisión de traducción, el traductor conservó y reprodujo la función comunicativa de dichas palabras. Ejemplo:

La mujer de pelo en el pecho (Vargas Llosa, 2013:358)

Жінка вона була хвацька (Варгас Льоса, 2014:150)

Usted es un hombre de muchos huevos, toda Piura lo dice (Vargas Llosa, 2013 :360)

Ви мужній чоловік, уся П'юра иче каже (Варгас Льоса, 2014 :156)

El par de huevos mejor puestos que hay en Piura (Vargas Llosa, 2013:381)

Він найбільший сміливець у цілій П’юрі. (Варгас Льоса, 2014:159)

¡Un matrimonio que además no vale un carajo! (Vargas Llosa, 2013:414)

До того ж їхній илюб мідяка не вартий! (Варгас Льоса, 2014 :172)

3. Uso de disfemismos. Al traducir malas palabras, esta estrategia le permite reforzar el significado ofensivo, grosero e inaceptable de la palabra. Esta técnica es apropiada cuando la traducción literal o perífrasis suaviza mucho el significado de la palabra y puede llevar a la pérdida del colorido emocional del texto. Ejemplo:

Deja de hacerte pelotudo, que no te sienta nada (Vargas Llosa, 2013:414)

Не вдавай дупеля, тобі иее не личить (Варгас Льоса, 2014 :172) 
Te has metido en un grandísimo lío del corajo (Vargas Llosa, 2013:417)

Можемо запевнити, щчо ти по вуха в лайні (Варгас Льоса, 2014 :173)

Un huevón a la vela eso es lo que soy (Vargas Llosa, 2013 :261)

Таким собі довбаком на поготові (Варгас Льоса, 2014 :111)

Si a Dios o al demonio les quedaba un soplo en el cuerpo, continuó, aquel mundo de mierda se acabaría para siempre...(Ruíz Safón, 2016 :150)

Якщи в Бога чи в диявола лишилась ще хоть краплина порядності, вів далі Фермін, цей блядський світ мусить навіки згинути... (Руїс-Сафон, 2018:59)

4. Uso de equivalente dinámico. Esta estrategia tiene como objetivo aproximar la reacción emocional y estética de los lectores de la traducción a la reacción de los lectores del original, pero, como señala Y. Naida, la identidad en detalle en tal técnica de traducción, no puede ser. Ejemplo:

Váyase a paseo (Ruíz Safón, $2016: 205)$

Idimb до бica (Pуїс-Сафон, $2018: 80)$

... y menos lo que hacía dejándose embaucar por esa chola de mierda con la que fue a enchucharse (Vargas Llosa, 2013 :423)

... а надто, коли дав себе окрутити изій смердючій метисці, з якою злягався (Варгас Льоса, $2014: 175)$.

\section{Conclusión}

Así pues, el material que hemos estudiado muestra que al traducir lenguaje malsonante de obras literarias españolas y latinoamericanas, los traductores utilizan diversas estrategias destinadas no solo a reproducir el contenido temático de la obra, sino también a conservar el nivel emocional y estético del original y el estilo del autor. La clase más común incluye, en primer lugar, traducción literal, perífrasis, uso de disfemismos y equivalentes dinámicos. Son estas técnicas las que permiten al traductor transmitir mejor las funciones semánticas y comunicativas de los elementos léxicos obscenos utilizados por el autor de la obra.

Un análisis léxico-semántico y funcional-estilístico más completo de textos literarios para el uso del léxico de esta capa permitirá identificar y caracterizar su profundo trasfondo emocional y estético de reproducción artística de la imagen expresiva del mundo trivial cotidiano, donde tienen valor no solo imagen estética, pero también el estilo de vida de una persona, su vida cotidiana.

\section{Literatura}

Vynogradov, V. (1987). Leksicheskiye voprosy khudozhestvennoi prozy [Lexical issues of translation of fiction] p. 8. Moskva [in Russian].

Dyamel, Zh. (1983). Dostavit chitatelyu udovolstviye [To please the reader] pp. 106-107. Homo legens. Moskva: Progress [in Russian].

Novikov, L. (2003). Hudozhestvenniy tekst i ego analis [Fictional text and its analysis]. pp. 26-29. Moskva: Editorial USRR [in Russian].

Nekriach, T. (2008). Pereklad khudoznikh tvoriv. Cherez terny do zirok [Translation of works of arts. Trough the thorns to the stars]. pp. 11-14. Vinnytsia: Nova Knyga [in Ukranian].

Modestov, V. (2006). Khudozhestvennyi perevod: istoriia, teoriia, praktika [Literary translation: history, theory, practice]. Moskva [in Russian]. 
Stavytska, L. (2008). Ukrainska mova bez tabu [Ukranian language without taboo]. Kyiv [in Ukranian].

Kleputs, L. (2009). Strategii klasyficatsii nenormativnoi leksyky [Strategies for the classification of profanity]. Humanity and social science. Lviv. Ukraine: Lvivska politekhnika.

Zhelvis, V. (2001) Pole brani: Skvernoslovie kak socialnaya problema v yazukah y kulturah mira [Battlefield: Bad Language like a social problem in languages and cultures of the word]. Moskva: Ladomir [in Russian].

Formanova, S. (2013). Stylistycni ososblyvosti invectyvy v ucrainskiy movi [Stilistic features of the invective in Ukranian lenguage]. Zapiski z ukrainskogo movoznavstva. No 20. pp. 121-131. [in Ukranian].

Zhusupova, A. (2004) Osobennosti prevoda nenormativnoi leksiki v sovremennoi angliyskoi literature [Features of translation of non-normative vocabulary in modern American literature]. Retrivered from http://www.rusnauka.com/6_PNI_2014/Philologia/7_161474.doc.htm [in Ukranian].

McEnry, T. (2006) Swearing in English: bad language, purity power from 1586 to the present. New York: Routledge

Andersoon, P., \& Trudgill, P. (1992). Bad language. London.

Fälthammar Schippers, A. (2014) Bad Language in Reality: A study of swear words,

expletives and gender in reality television. Retrivered from https://gupea.ub.gu.se/handle/2077/35743

Avila-Cabrera, J. Propuesta de modelo del análisis del lenguaje ofensivo y tabú en la subtitulación (2015) [Proposal of a model for the analysis of offensive and taboo language in subtitling] Revista Electrónica de Lingüística Aplicada, (12),37-56. doi: 10.4995/rlyla.2015.3419 [in Spanish].

Buzadzhy D.M. (2006). Norma nenormatyvnoho: ruhaemsia adekvatno [The norm of non-normative: we swear adequately]. Mosty. № 1 (9). P. 43-55. [in Russian].

Rojo López, A. M., \& Valenzuela Manzanares, J. Sobre la traducción de las palabras tabú [Translation of the taboo words] (2000). Revista De Investigación Lingüistica, 3(1), pp. 207-220. Retrivered from: https://revistas.um.es/ril/article/view/4351 [in Spanish].

Ruiz Safón, C. El laberinto de los espiritus [The Laberinth of Spirits] (2016). Barcelona: Planeta [in Spanish].

Ruiz Safón, K. (2018). Labirint duhiv [The Laberinth of Spirits ]. (O. Lesko Trans). Kharkiv: Klub simeynogo dozvilla [in Ukranian].

Vargas Llosa, M. Héroe discreto [Discreet hero] (2013). Paperback [in Spanish].

Vargas Liosa, M. (2014) Skromnyi geroy [Discreet hero]. (S. Borschevskiy Trans). Kharkiv: Folio [in Ukranian]. 